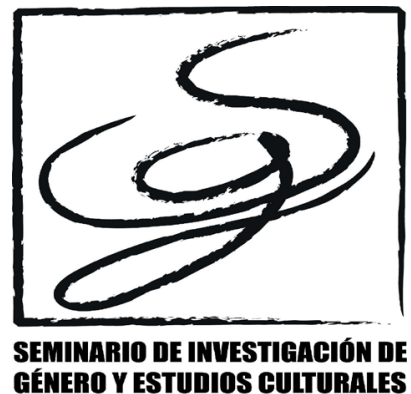

\title{
Derecho a la salud materna de las mujeres ngäbes y buglés en Costa Rica. Mitos, percepciones y discriminación
}

Right to maternal health of Ngäbe and Bugle women in Costa Rica. Myths, perceptions and discrimination

\author{
Ana Sofía Solano Acuña \\ Universidad Nacional-Costa Rica \\ ana.solano.acuna@una.ac.cr
}

Fecha de recepción: 24/03/2020 Fecha de evaluación: 06/05/2020

Fecha de aceptación: 24/11/2020

\begin{abstract}
:
The present work is the result of a long process of contact with the indigenous ngäbe and buglé population residing in Costa Rica, as well as with those who have been forced to travel to work temporarily in the coffee harvest and the pinch of coffee. fruit. It is important to define as a starting point that the migration of this indigenous people in recent years has disrupted the identity construction of the Costa Rican, who had kept the indigenous presence in the cities of the center of the country in the shadow, displacing these identities to historically peripheral areas and rural. Through these pages I will try to offer readers a historical and social context of what has been the incorporation of the ngäbe and buglé population from the second half of the century XX, I will immediately define some elements of a conceptual and methodological that I consider essential to understand these presences, relationships and negations. I continue to single out the case of indigenous women facing displacement (Panamanians) or the myth of foreigners (Costa Ricans), and how they cope with the experience of pregnancy, childbirth and postpartum in a context of social exclusion. I conclude the reflection by offering an overview of the myths, perceptions and difficulties that underlie health personnel and that seriously hinder the possibility of establishing care spaces free from all forms of gender violence and ethnic discrimination.
\end{abstract}

Key-words: migration; cross-border peoples; gender violence; obstetric violence; historical racism 


\section{Resumen:}

El presente trabajo es el resultado de un largo proceso de contacto con la población indígena ngäbe y buglé residente en Costa Rica, así como, con aquella que se ha visto obligada a desplazarse para trabajar de manera temporal en la cosecha de café y la pizca de fruta. Es importante definir como punto de partida que la migración de este pueblo indígena en los últimos años ha trastocado la construcción identitaria del costarricense, que había mantenido bajo la sombra la presencia indígena en las ciudades del centro del país desplazando estas identidades a zonas históricamente periféricas y rurales. A través de estas páginas intentaré ofrecer, a las personas lectoras, un contexto histórico y social de lo que ha sido la incorporación de la población ngäbe y buglé a partir de la segunda mitad del siglo $X X$, de inmediato definiré algunos elementos de carácter conceptual y metodológico que considero fundamentales para comprender estas presencias, relaciones y negaciones. Continúo particularizando el caso de las mujeres indígenas enfrentadas al desplazamiento (panameñas) o al mito de foráneos (costarricenses), y cómo hacen frente a la experiencia de embarazo, parto y posparto en un contexto de exclusión social. La reflexión la concluyo ofreciendo un panorama de los mitos, percepciones y dificultades que subyacen en el personal de salud y que dificulta gravemente la posibilidad de constituir espacios de atención libres de toda forma de violencia de género y discriminación étnica.

Palabras clave: migración; pueblos transfronterizos; violencia de género; violencia obstétrica; racismo histórico

\section{Antecedentes}

El pueblo guaymí ${ }^{1}$, compuesto por ngäbes y buglés suma un total de 9.543 personas que habitan en Costa Rica (INEC-Costa Rica, 2011) y de 285.033 en Panamá (INEC-Panamá, 2010). Esta sociedad indígena pertenece a la estirpe chibchense (Constenla Umaña, 1991; Hasemann, Lara Pinto, y Cruz Sandoval, 1996), es la etnia más populosa de toda la Baja Centroamérica. Así mismo es la que se encuentra en condición de mayor pobreza y posee, en ambos países, indicadores que hablan de una alta marginalidad con respecto a otros pueblos indígenas y a las poblaciones mestizas.

Esta población indígena posee dos lenguas perfectamente identificables, el ngäbere y el buglére. La primera, según Quesada (2012) es la lengua de la familia chibcha que posee el mayor número de hablantes, aproximadamente 150.000 personas. En el presente etnográfico, se pueden ubicar uniones matrimoniales entre personas que

\footnotetext{
${ }^{1}$ Este es un etnónimo que se puede rastrear hasta las fuentes españolas en los períodos de conquista y colonización, en los últimos 30 años ha ido quedando en desuso por la reinvindicación de los etnónimos ngäbe y buglé pero en algunas localidades de ambos países de estudio aún se utiliza.
} 
hablan lenguas diferentes y se desarrollan ambientes bilingües $o$ poliglotismos familiares al interno del mundo indígena.

En Panamá la población indígena ngäbe y buglé se distribuye en Chiriquí, Bocas del Toro, Veraguas y una importante cantidad en la Ciudad de Panamá como migrantes laborales. En el año de 1997 luego de una larga lucha, a través de la Ley $N^{\circ} 10$, Gaceta Oficial $N^{\circ} 23.242$ se crea la Comarca Ngäbe-buglé con un área de $6968 \mathrm{~km}^{2}$. Dicha Comarca se constituye a partir de territorio de Bocas del Toro, Chiriquí y Veraguas, y su cabecera es Llano Tugrí.

En el territorio costarricense se ubican en cinco territorios indígenas: Abrojo Montezuma (reconocido en 1980), Altos de San Antonio (reconocido en 2001) y Conte Burica (reconocido en 1982) en el cantón de Corredores, y Coto Brus (reconocido en 1981) en el cantón de ese mismo nombre. $Y$ finalmente, Alto Laguna de Osa (reconocido en 1993) se ubica en el cantón de Golfito y colinda con el Parque Nacional Corcovado. Al igual que en Panamá, también se localiza población guaymí dispersa en otras partes del país, principalmente en aquellas zonas donde son requeridos como trabajadores temporales (cosecha de café, pizca de fruta, zonas bananeras, entre otros) redoblando con esto su condición de vulnerabilidad social.

La conformación de los territorios en Costa Rica son el resultado de un proceso de desplazamiento de grupos familiares, principalmente de Chiriquí, en los años cuarenta del siglo XX en búsqueda de nuevas tierras para asentarse y producir su sustento. Hasta el año de 1991 el Estado de Costa Rica mediante la Ley $N^{\circ} 7225$, Ley de inscripción y cedulación indígena, declara la obligación del Estado de otorgar cédulas de identidad costarricense a los guaimí (Guevara Berger, 2000). Esta experiencia fue fundamental para el movimiento indígena en este país ya que por primera vez la Sala Constitucional resuelve amparándose en el Convenio 169 de la Organización Internacional del Trabajo, el cual junto con la Declaración de los Derechos de los Pueblos Indígenas constituyen los bastiones más importantes en materia jurídica actualmente vigente en Costa Rica.

Antes de este proceso, toda persona ngäbe 0 buglé era considerada extranjera, lo cual dificultaba el acceso a servicios básicos. El estigma de "migrante panameño" sirvió como excusa para la inoperancia del Estado en problemáticas tan trascendentales como tenencia de tierra, educación, salud y acceso a la justicia. Esta posición de considerarlos extranjeros contradecía la declaración oficial de los territorios que para entonces ya se había reconocido en la zona sur del país, así como la presencia concreta y materialmente comprobable de importante población nacida y criada en territorio costarricense.

Lamentablemente como expondré en los siguientes apartados, la idea de "foráneo", "migrante" o "panameño arrimado" continúan siendo parte del diario vivir de esta población, del escenario donde los "otros" construyen sus relaciones con ellos, así como de los estereotipos y mitos que dificultan poder establecer relaciones equitativas. Esta situación se 
hace aún más compleja cuando se entrecruza con construcciones de género patriarcales, prácticas xenofóbicas y racistas.

El tico no conocía de la existencia de los indígenas, los creía enterrados e inofensivos y por lo tanto no podían ser sujetos de odio, rencor y violencia. Solo tenía sentimientos de curiosidad cuando por casualidad y en rara vez conocía a un indio de cualquier país o del propio (Borge Carvajal, 1978: 347).

Durante la larga contienda por la delimitación fronteriza (resuelta hasta la primera mitad del siglo XX), hubo una importante generación de estudios e informes donde en ocasiones los "indios guaymí fueron objeto de algunas cuantas líneas. En ellos cuando se abordó su presencia fue con el objeto de argumentar la posesión de una u otra nación sobre las tierras que habitaban, esta condición cambió abruptamente cuando se delimitaron las fronteras y en consecuencia ninguna de las partes los asumió en sus construcciones de ciudadanía. Al mismo momento, la presencia indígena que yacía aún en los pueblos y ciudades como Penonomé (y de los cuales existe registro documental) al centro occidente de Panamá paulatinamente fueron registrados por la administración como "cholos" 2 lo cual constituyó la base de un complejo proceso de desindianización.

El uso de la palabra cholo, para el caso panameño, se atribuyó casi que exclusivamente a personas con vinculación a los pueblos del occidente panameño, y desde su "popularización" a finales del siglo XIX ha sido punta de lanza para desarticular (política e ideológicamente) cualquier intento de levantamiento indígena donde los sectores mestizos fuesen convocados. El sector de los cholos es mutilado del mundo indígena y pensado de forma negativa, atribuyéndole una identidad borrosa y una doble negación pues no es indio, pero tampoco es ladino.

Algunos autores como Morales y Lobo (2014), han planteado que la población ngäbe y buglé es "nómada" como parte de su cosmovisión, sin embargo, la información documental existente desde finales del siglo XIX explica que esta movilización ha sido una forma de sobrevivencia a las presiones sostenidas sobre su territorio histórico hasta el presente.

Barrantes (1982) por su parte ofrece una explicación de cómo ha sido el desplazamiento y la conformación de nuevos espacios de hábitat, a partir de los estudios de genética de poblaciones que se han realizado en la población de los territorios costarricenses. El autor plantea que en un primer término ocurrieron fisiones de grupos emparentados en Panamá, que gradualmente emigraron hasta las localidades de Costa Rica; aquí los diferentes grupos se fusionaron para establecer poblaciones de alrededor de 300 habitantes a unos $200 \mathrm{~km}$ del lugar de

\footnotetext{
2 Se comprende como un sector intermedio, menos seguro para quienes ostentan el poder que la identidad indígena a la que consideran su alter-ego. La existencia del cholo desdibuja las fronteras de la sociedad estamental heredada de la colonia, le da agencia de cambio y trasformación al mundo indígena que se ha construido y definido como algo monolítico que desaparece al menor cambio.
} 
origen. Este fenómeno se conoce como el modelo de "fisión-fusión" y de "efecto lineal" que indica que la emigración se da entre grupos emparentados. Una vez que estos grupos alcanzan el nivel óptimo de su población se inician procesos nuevos de desplazamientos, los principales detonantes son la estructura demográfica y el espacio físico disponible.

Esta situación explica la constancia en el arribo a territorio costarricense de población proveniente de Panamá, a veces como trabajadores temporales, pero también para residir de forma permanente en alguno de los cinco territorios reconocidos por el Estado.

En reportaje del periódico La Nación del día 1 de octubre del 2006, se narra la experiencia de vida de Benedicto Bejarano Sandoya (quien no recuerda su edad), su esposa, su suegra y sus cinco hijos menores de edad quienes tenían siete meses de residir debajo del puente del Rio Abrojo, a falta de tierra y vivienda. A pesar de la cercanía del Territorio Indígena de Abrojo Montezuma, Benedicto explica al periodista que no pertenecen a esa comunidad, que son de otro grupo en busca de lugar donde vivir. Además, narra que su situación es difícil:

\begin{abstract}
hay días en que debemos acostarnos sin probar bocado porque no tenemos qué cocinar. El arroz y los frijoles los comemos de vez en cuando. Mire a mi hijo Jorge: hace rato que destapa la olla que está en el fuego y no tiene nada. De seguro que él tiene hambre (Marvin Barquero, "Familia indígena sufre penuria bajo un puente".
\end{abstract}

Ellos exponían que en los meses que tenían de vivir bajo el puente, no habían recibido la visita de funcionarios del Gobierno que determinan si son aptos para un bono de vivienda o un subsidio económico.

En cuanto a los trabajadores temporales, estos nos abren la puerta a un nivel mayor de dificultad y de exclusión, los mismo ingresan al país por el lapso de algunos meses al año para la cosecha de café y/o para el trabajo en las bananeras. La frontera entre ambos países consiste en $330 \mathrm{~km}$ de trecho que va desde la costa costera del Pacífico, continua por la Cordillera de Talamanca hasta llegar a la zona costera del Caribe. Funciona como una membrana porosa donde los trabajadores temporales se desplazan entre ambos países, existen tres puestos fronterizos: Rio Sereno, Paso Canoas y Sixaola-Guabito. Los dos primeros, muy utilizados por los trabajadores temporales que se dirigen a las cosechas de café ya sea en las fincas del cordón fronterizo o en las del Valle Central del país, como Naranjo o Los Santos. El tercer puesto es mayormente utilizado por los trabajadores que se desempeñan en la actividad bananera. 


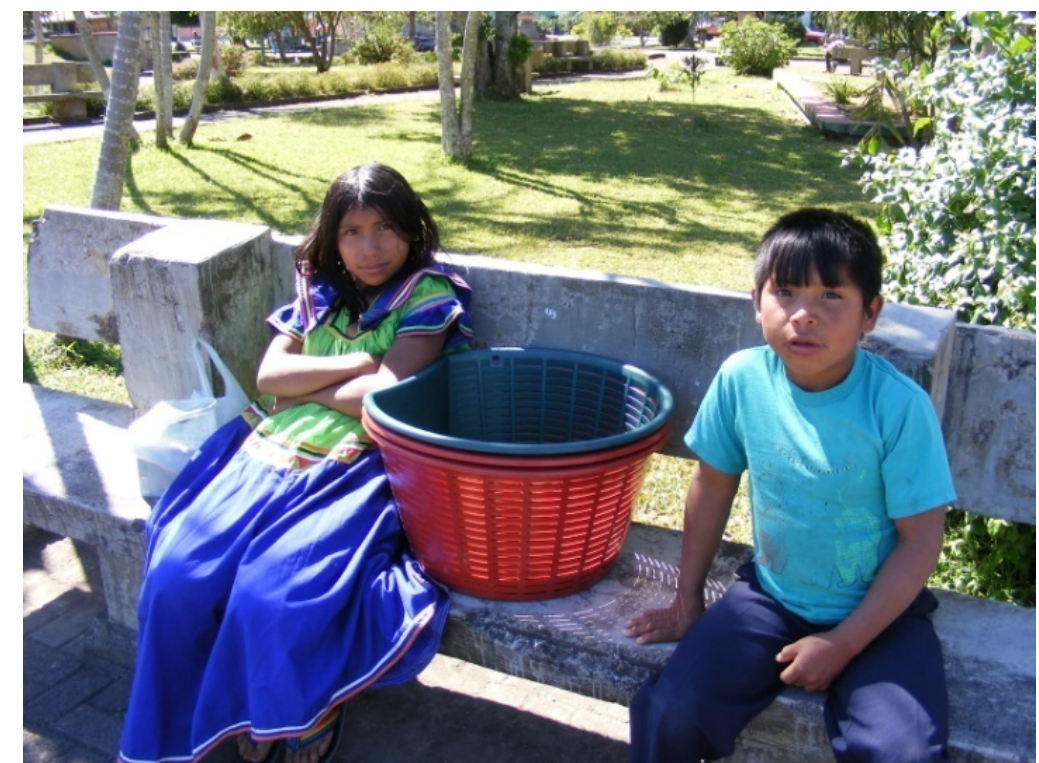

Fotografía 1. Niños cosechadores de café en el parque de Santa María de Dota. Fuente: Colección personal de la autora. 2008.

La actividad del café es la que atrae más trabajadores en promedio, según las autoridades de ambos países la cantidad de personas podría oscilar entre 6.000 y 14.000 aproximadamente por año de cosecha. Sin embargo, se mantiene un subregistro alto y no se puede saber con mayor certeza realmente cual es la magnitud de dicha movilización. Se puede constatar en los testimonios de muchos productores costarricenses, que esta actividad económica depende principalmente del arribo de esta mano de obra año con año.

En relación con la actividad bananera las autoridades migratorias calculan unas 3.0000 trabajadores al año de igual forma con un subregistro alto.

Para la actividad del café, la migración de población indígena está conformada, en gran medida, por núcleos familiares completos, que se asientan en las fincas y tratan de reproducir la dinámica familiar y comunal que podrían encontrar en sus lugares de origen. Por ejemplo, en algunas de las visitas a fincas cafetaleras, he podido observar cómo los adultos mayores realizan una labor de cuido, de trasmisión de la cultura, principalmente, a través de la lengua e inclusive con niños y niñas que no pertenecen a su núcleo familiar directo. En esta misma se podría incluir a las mujeres parteras, que son un elemento vital en aquellas fincas alejadas, o inclusive con dificultad de acceso del personal de salud por lineamiento del dueño de la finca. El recorrido de los cosechadores de café inicia en Coto Brus en noviembre y finaliza en Los Santos y el Valle Central a comienzos de marzo, siguiendo el proceso de maduración del fruto en esas distintas localidades 


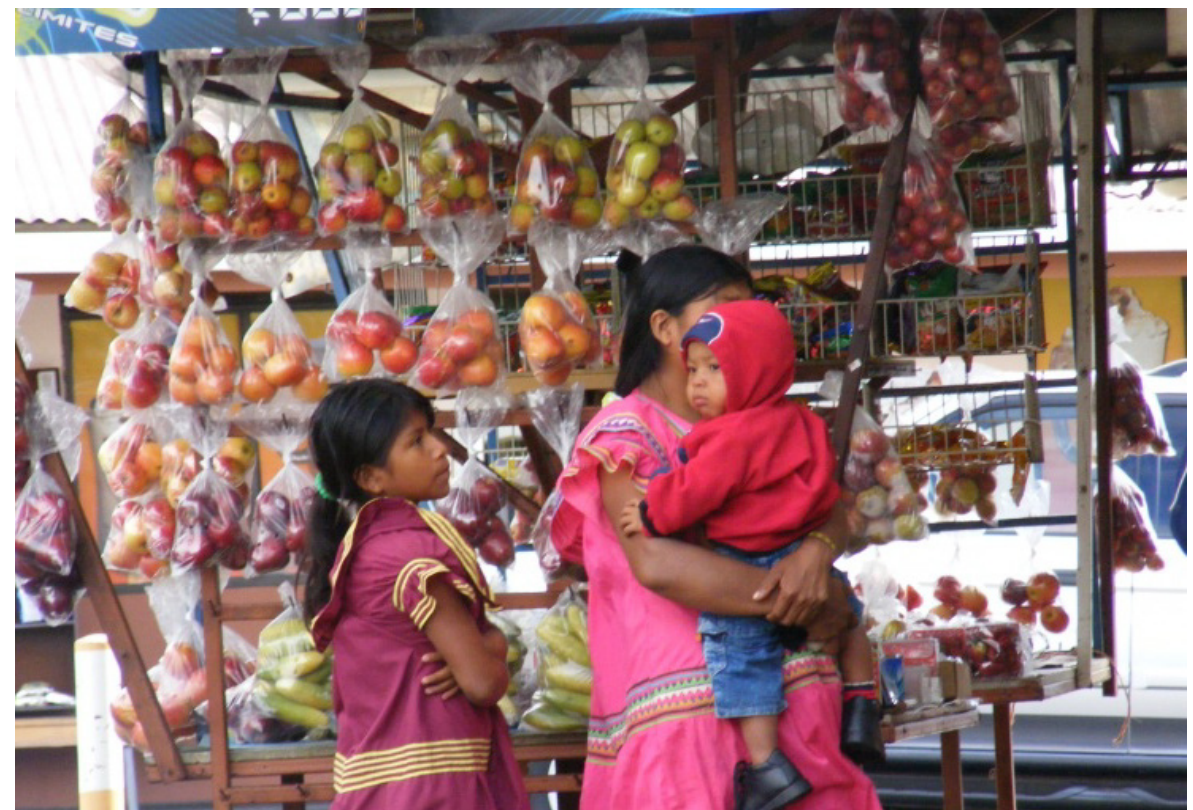

Fotografía 2 Mujer con niños en la Carretera Interamericana.

Fuente: Colección personal de la autora. 2011.

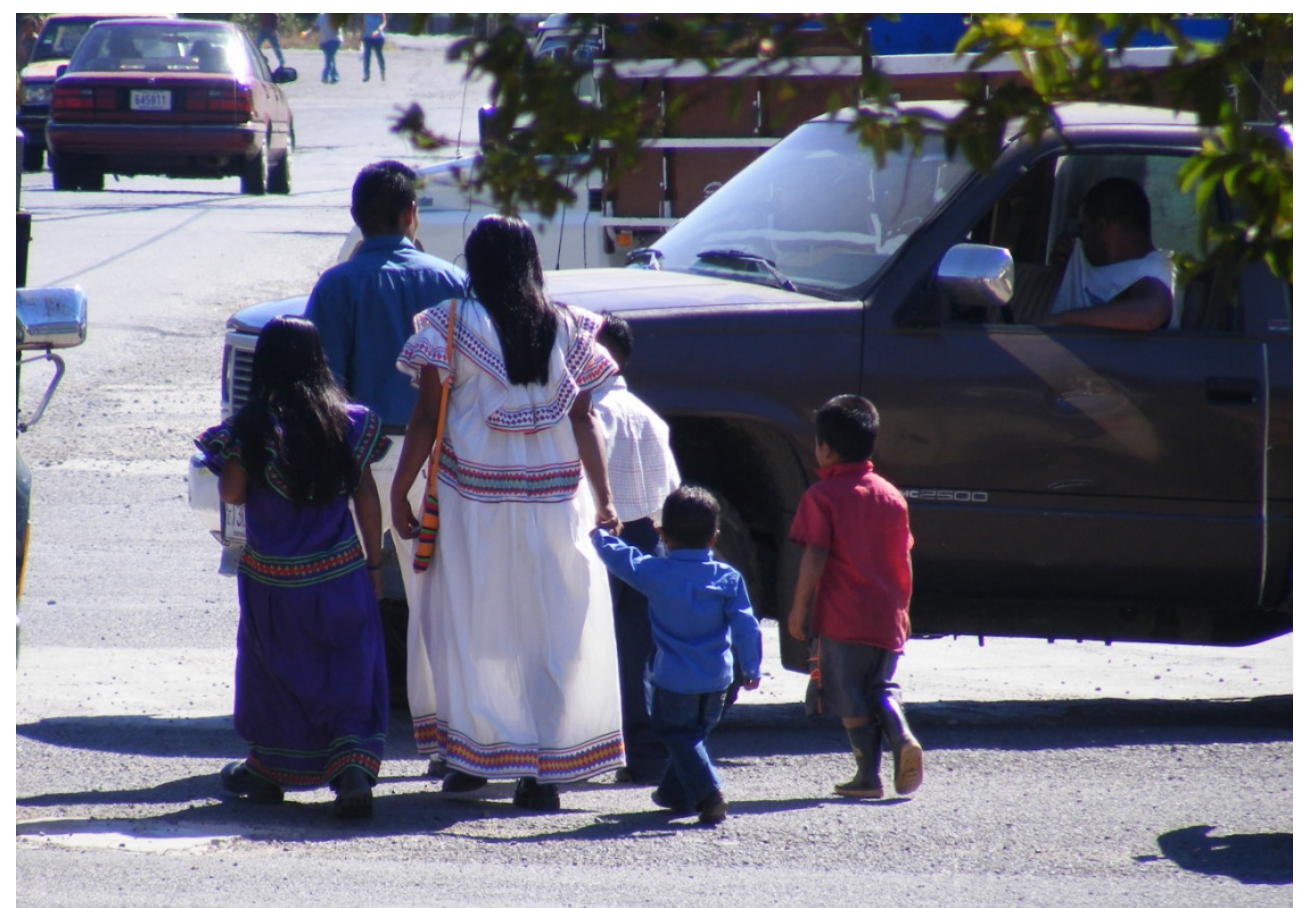

Fotografía 3. Grupo familiar en Santa María de Dota un día domingo.

Fuente: Colección personal de la autora. 2010.

Respecto a la actividad bananera, esta define como principal sector migrante a los hombres, en parte por el tipo de trabajo, pero también por la dinámica de contratación y estancia propias en las fincas de banano. La actividad del banano al no ser estacional requiere mano de obra durante todo el año por lo que los obreros pueden permanecer largos períodos.

Los lugares de mayor expulsión de población indígena en el occidente de Panamá son los distritos de Kankintú, Kusapin, Besikó, 
Muná y Mrono, que son parte de la Comarca Ngäbe-buglé; así como San Félix, Tolé, Chiriquí Grande y Changuinola.

El 17 de mayo del 2012 se publicó el Reglamento de Extranjería y en el Título $V$ se desarrolla el tema "Tratamiento a poblaciones indígenas extranjeras" en el que se establecieron las siguientes categorías migratorias: a) Residente permanente y temporal, b) Categoría especial: Trabajador temporal, c) Categoría especial: Trabajador transfronterizo; d) Categoría especial: estudiante.

En la cosecha de café participa, en su mayoría, población proveniente de Panamá, aunque algunas familias de Coto Brus ya tienen contratos anuales en fincas particulares para ir a la cosecha. En este sentido, ser costarricense o ser panameño implica para el trabajador indígena y su familia una mayor o menor protección en cuanto al "bache", las jornadas de trabajo, la paga por cajuela ${ }^{3}$ y hasta algunos mecanismos que utiliza el finquero para asegurar mano de obra durante toda la cosecha ${ }^{4}$.

Las familias indígenas costarricenses prefieren dirigirse a fincas del Valle Central pues consideran que los patronos están mucho más dispuestos a brindar mejores condiciones de trabajo, además viajan en grupos, el transporte lo envía la finca y van con trabajo asegurado. La oportunidad de salir del territorio indígena a la cosecha de café implica un ingreso extra para "la entrada a clases de los muchachos", también para comprar semilla o insumos agrícolas. En una ocasión unas muchachas de entre 16 y 20 años me compartieron que, además de ayudar a su familia, el encuentro que se da a propósito de la cosecha con personas ngäbes y buglés de Panamá o de otras partes de Costa Rica, también constituía una oportunidad para establecer nuevas relaciones de parentesco pues en su comunidad de origen "todos son familia". La mayoría de estas familias poseen tierras en los territorios reconocidos, y complementan su subsistencia con lo que en ellos produzcan y otras actividades tales como la artesanía.

Las familias indígenas panameñas tienen la situación un tanto más difícil que sus homólogos costarricenses; en principio su manejo del castellano y en general del mundo económico-laboral fuera de la Comarca es reducido, lo cual los hace muy vulnerables a estafas y depreciación de su trabajo. Algunos no ingresan con trabajo asegurado, sino que llegan al país en busca que opciones y es común en las zonas productoras de café la reunión de familias indígenas en "puntos de contratación". Para la zona de Los Santos las cafeterías a lo largo de la Carretera Interamericana son una opción, y es común ver como las familias lideradas por el varón se reúnen alrededor de los pocos teléfonos públicos que aún existen e

\footnotetext{
${ }^{3}$ En Costa Rica la forma de pago es por cajuela, la misma mide $27 \mathrm{~cm}$ por $27.50 \mathrm{~cm}, 20$ cajuelas hacen una fanega, una fanega es equivalente aproximadamente a un quintal de café oro.

${ }^{4}$ En las fincas del cordón fronterizo es común que algunos finqueros retengan un porcentaje del precio a pagar por cajuela, el cual se entrega hasta que la cosecha termina. Esta práctica es una forma de retener a los trabajadores en sus fincas y garantizarse los brazos requeridos para cosechar su producción.
} 
inician esa labor de contactar a finqueros de la zona que requieran de cosechadores. También existe la modalidad de "encargo" y se da cuando algún dueño de finca contacta con una persona indígena y "manda a traer" mano de obra desde Panamá, es importante anotar que en esta travesía se puede durar varios días desde la salida de su hogar hasta la llegada algún lugar de trabajo. Como en la mayoría de los procesos migratorios las mujeres, los niños y niñas y las personas adultas mayores son las que se encuentran en mayores condiciones de vulnerabilidad $y$, por ende, son descartados para este tipo de trabajos que conllevan esfuerzo físico.

Para los productores de café la contratación de mano de obra indígena tiene varios réditos, uno de ellos es la capacidad de la organización interna de la finca de la finca, es decir, que el patrono se entiende con un representante de los trabajadores y este a su vez es el enlace con los trabajadores y las trabajadoras. Otro de los atributos que los productores de café encuentran en la contratación de trabajadores indígenas, es la facilidad de llegar a acuerdos (precios, horario, condiciones de trabajo) en comparación con otro tipo de trabajador como es el caso de los nicaragüenses.

Finalmente, la composición familiar de los grupos de trabajadores migrantes es otro atractivo para los finqueros, pues la convivencia en la finca es más llevadera que en el caso de grupos de trabajadores compuestos exclusivamente por varones. A diferencia de otros procesos migratorios en la región, la migración de esta población indígena, tanto a mediados del siglo XX como en la actualidad, ha tenido como característica la presencia de mujeres, adultos mayores e infantes en cantidad importante.

La movilidad, para el caso de las mujeres indígenas, está orientada a mercados de trabajo precarios, devengando horarios laborales iguales a los varones en el campo, y resolviendo el trabajo doméstico y de cuidado. Su situación se ve encarecida aún más cuando los arreglos económicos se realizan con sus maridos, padres o hermanos, creando una condición de dependencia económica absoluta.

Sin embargo, la situación de vulnerabilidad de estas mujeres se agrava al momento en que ellas migran. EI hecho de estar fuera de sus lugares de origen las coloca como extranjeras, aunque se encuentren en su propio país. Esto es así por su condición étnica, lo que las hace vulnerables a la discriminación que sufren por la población mestiza, y lo que justifica las condiciones de empleo y de vida que se les ofrecen en los lugares de destino, sobre todo para las trabajadoras domésticas y las jornaleras agrícolas (Lara, 2009: 34).

Nacer como mujer en el contexto de una sociedad patriarcal, suele traducirse en que sus cuerpos sean valorados únicamente como objeto del deseo masculino, situación que las ubica como blancos potenciales de violaciones o explotación sexual en el transcurso de su viaje o en los espacios laborales de llegada. 


\section{Perspectiva conceptual}

En el Artículo 1 de la Convención Interamericana para Prevenir, Sancionar y Erradicar la Violencia contra las Mujeres (1994) se entiende como violencia "cualquier acción o conducta basada en su género, que cause muerte, daño, sufrimiento físico, sexual o psicológico a la mujer, tanto en el ámbito público como privado". Bajo este concepto también quedan amparados los casos de violencia obstétrica, los cuales no se circunscriben solamente en el ámbito hospitalario, sino que incluyen también la consulta prenatal y post natal, tal como lo estima el Centro por la Justicia y el Derecho Internacional (CEJIL).

La violencia obstétrica, más puntualmente hablando, es un conjunto d prácticas que degrada e intimida a mujeres y niñas principalmente en el período del embarazo, parto y postparto. Este tipo de violencia se ejerce a través del poder obstétrico, el cual tiene como fin crear cuerpos sexuados, dóciles y manejables (Arguedas Ramírez, 2014: 147).

Barsley (2008) propone que el cuerpo ha sido utilizado más en el rol de receptor, reflejando constantemente los efectos de las fuerzas socio-político-ideológicas impregnadas en él. Sus capacidades para interpretar y generar la vida han sido delimitadas por los territorios impuestos políticamente. La medicalización del embarazo y el parto constituyen, por lo tanto, el eje medular de la colonización del útero y del cuerpo de las mujeres (Arguedas Ramírez, 2014). Tristán Platt (2002) en un ejercicio por explicar, desde la vivencia indígena, que entiende por un "parto normal" lo define básicamente como un parto doméstico, donde la madre es atendida por su marido e hijos, y cada uno tiene una función, ya sea, hervir agua, preparar infusiones, buscar utensilios o hacerse cargo de los más pequeños. Contrario a esta escena, el parto occidental es percibido, prioritariamente como actividad uterina, que se da en soledad, y como acción médica ejercida sobre un cuerpo femenino al que se le roba con frecuencia su condición de sujeto moral (Gupta y Nikodem, 2000). Sobre este modelo:

\footnotetext{
Los partos en casa se consideran un signo de retraso, de irresponsabilidad o de pobreza y la figura de la partera es, para una gran mayoría, un signo de lo rural, de lo pre-moderno, contrario a lo citadino y lo civilizado (Arguedas Ramírez, 2014:157).
}

La desigualdad no sólo debe ser comprendida como una consecuencia de una distribución injusta de los bienes económicos y sociales, sino también, del reconocimiento como es el caso de los pueblos indígenas y sus saberes (Clérico y Aldao, 2011).

El principio antidiscriminatorio puede funcionar ante discriminaciones puntuales, pero no logra dar cuenta de la desigualdad que responde a una diferencia sistemática y estructural. Los grupos subalternos no pueden resolver su situación de desigualdad en soledad, sino que se requieren medidas de acción positiva, reparadoras o 
transformadoras para lograr igualdad real de oportunidades para el ejercicio de los derechos (Clérico y Aldao, 2011).

\section{Apuntes metodológicos}

Para la reflexión que realizo en estas páginas, me he basado en el seguimiento de la temática y población desde hace trece años, para lo cual he tenido como principal fuente de consulta mis cuadernos de campo. En el proceso de exploración del tema del embarazo y parto que inició a eso del año 2007, se trabajó mediante entrevistas semiestructuradas a mujeres que habían tenido experiencias de embarazo y parto. En algunas ocasiones se entrevistó a personas que solamente habían sido atendidas por la vía tradicional, y otras ocasiones a personas que habian tenido la experiencia de atención a través de los dos sistemas de salud. También se han realizado entrevistas y grupos de discusión con personal de salud del sistema estatal y con especialistas indígenas; $y$ se ha complementado el estudio de las percepciones de los costarricenses respecto de los pueblos indígenas en encuestas de opinión y también en análisis de prensa. Es decir, que el análisis aquí presentado es el resultado de una conjunción de varias técnicas de investigación exploradas por un período largo de tiempo, que permitan reconstruir de laguna manera la situación de los migrantes indígenas, en especial de las mujeres en embarazo.

\section{Resultados de la investigación}

\subsection{Las mujeres ngäbes y buglés}

Rompiendo el mito de los "indígenas panameños", muchas de las mujeres indígenas que son atendidas en los servicios de salud son costarricenses, ya sea porque nacieron en Costa Rica o porque han optado por la nacionalidad. Luego del proceso de 1992, al que hice referencia paginas atrás, esta opción es relativamente sencilla para una persona ngäbe o buglé pues consta de un trámite donde debe presentar dos testigos como requisito.

Yo no nací aquí, yo soy de Panamá...De Sereno para allá, de San Vito para allá... (¿Cómo llegó a Betania?) como yo no sabía mi mamá conoció aquí, la mamá de Víctor... Y llegó ahí y conoció eso, y todo esta fincas mi mamá conoce, al menos yo no conozco nada. Mi mamá llega detrás la tía, como dos con este tres me vine para acá. Ella tenía 8 meses (refiriéndose a Chami)...La papá de ese chiquito yo dejó porque tomaba mucho y peliaba conmigo, yo deje y me vine para acá con mi mamá. $Y$ después cuando tenía 8 meses esa chiquita me junte con este señor, con Ciriaco...Cuando tuvo casa ahí abajo yo estuvo viviendo con él, luego cuando vino un río grande creciente vinimos para acá" (Felicita Atencio Rodríguez (mujer indígena), en discusión con la 
autora, Territorio indígena de Coto Brus, noviembre 2007).

La edad a la que las mujeres indígenas empiezan su vida sexual y experimentan sus primeros embarazados oscila entre 14 y 16 años, aunque entre esta población sí se han presentado casos de niñas de 12 años. En términos de población femenina que ha nacido o vive de forma permanente en Costa Rica, se puede notar una diferencia con respecto a las que son parte del flujo migratorio laboral pues estas últimas carecen en mayor medida de información, los niveles educativos son mucho más deficientes y en general las condiciones de las fincas las expone mucho a situaciones de abuso sexual.

Yo cuando quedé embarazada ya yo tenía un amiga que me decía iusted sabe cómo queda en embarazo?, le dije no. Me decía que un embarazo, se forma un bebé adentro, aquí a uno; y a los 5 meses ya el bebé pone a moverse... y yo jamás pensaba eso porque a mi mamá cuando traía a mi hermano o a mi hermana, si es de noche ya yo no me daba cuenta, yo encontraba de mañanita a mi mamá con el bebé chiquitico. Yo le preguntaba y me decía: ¡Ah por ahí yo lo encontré! $Y$ por eso yo pensaba que yo lo iba a encontrarlo, pero una amiga mía me decía, que no, entonces yo peguntaba...Yo volví a ver a una señora embarazada y yo pensaba que de dónde lo sacaba. Ya estando yo embarazada le pregunté que por dónde tenían que sacarlo a él, y me dijo: Tienen que sacarlo por aquí. y yo jamás sabía (Ofelia Atencio Santos (mujer indígena), en discusión con la autora, Territorio indígena de Coto Brus, noviembre 2007).

En el caso de las generaciones de más de 30 años de edad, una gran parte de las mujeres panameñas y costarricenses no asistieron nunca a la escuela primera. Esta situación ha ido cambiando gradualmente, pues en Costa Rica todos los niños y niñas deben de asistir al menos a la escuela primera, en alguna medida este elemento ha apoyado el poder retrasar la edad de inicio de las relaciones sexuales, de los embarazos y las infecciones de trasmisión sexual. Sin embargo, las niñas y jóvenes se encuentran con el discurso patriarcal de "la tradición", y sobre este punto construyen y legitiman relaciones impropias donde las mujeres menores de edad, inclusive, son objetos intercambiables para el pago de deudas y demás.

Sobre este decir, en una ocasión trabajando en un grupo de discusión con las "abuelas", ellas reflexionaban sobre su propia experiencia, algunas fueron "intercambiadas" o "robadas" y estaban conscientes que esas prácticas eran profundamente lesionantes y una mala interpretación de lo que en algún momento fue la principal estrategia de cohesión de los ngäbes y buglés. En esa ocasión reflexionaron sobre cómo había "evolucionado" el concepto de familia y había encarecido cada vez más la situación de las mujeres, dado que en el pasado de 
existir un sistema poligínico (un hombre y varias mujeres) hoy en día lo común era un hombre que "usaba y desechaba" a mujeres más jóvenes, pero por lo general sin hacerse cargo de ninguna consecuencia. El sistema de Koba ${ }^{5}$ (Young, 1971), tiene poco que ver con la dinámica que afrontan hoy día las mujeres, tanto costarricenses como panameñas.

El trabajo económico remunerado de las mujeres ngäbes y buglés, en muchas ocasiones, es el principal o el único ingreso de los hogares, "la mujer guaymí desarrolla una gran capacidad laboral durante su vida activa, lo cual enriquece a las familias" (Torres de Araúz, 1999: 298). Su aporte va desde el trabajo en labores de campo, labores de manufactura (artesanía), labores de limpieza y cuido de personas, y en algunos casos (lamentablemente, aún no demasiados) en trabajos especializados o profesionales (esto principalmente, en la población femenina costarricense o que han sido criadas en el país). Toda la economía del cuidado recae sobre los hombros de las mujeres, principalmente las de más edad, que además son el principal vehículo de trasmisión de importantes elementos de la cultura como las lenguas. Sobre este último punto es de resaltar que, en el momento de la migración laboral, las abuelas son indispensables, pues en el espacio receptor realizaran esta labor para que las mujeres más jóvenes se sumen a la faena.

\subsection{El embarazo}

En promedio, las mujeres ngäbes y buglés tienen alrededor de seis hijos o hijas en aquellas que superan los 50 años de edad por lo general este número es mayor.

Entre las mujeres costarricenses y panameñas existen diferencias en cuanto a la atención hospitalaria durante un embarazo, las primeras, casi en su mayoría, declaran que sí estuvieron hospitalizadas mientras que las segundas no reciben atención de este tipo. Las que han experimentado abortos, han tenido sus pérdidas a eso de los 5 meses de gestación. Algunos de estos abortos se han dado por condiciones de salud propias de las mujeres, accidentes, agotamiento por las labores del hogar o el campo, o en ocasiones alguna situación de violencia de género.

Según Pernudi, Sandoval y Solano (2007), de noventa y cuatro mujeres entrevistadas en total, que habían tenido experiencia de embarazo, la edad promedio a la que tuvieron su primer embarazo fue a los 15 años de edad.

El embarazo mientras más cerca se encuentre de la menarquía suele ser más peligros, y según los especialistas a los 5 años de edad ginecológica es cuando la mujer alcanza la madurez (Peláez Mendoza,1997). Durante un embarazo temprano se pueden desarrollar el síndrome hipertensivo, preeclampsia, anemias, infecciones del tacto urinario, rotura prematura de membranas, niños nacidos con bajo peso,

\footnotetext{
${ }^{5}$ Sistema de parentesco basado en el intercambio de esposas entre dos familias, donde los pactos se realizaban para cohesión territorial, económica y política. Es importante resaltar que era una negociación entre los grupos familiares, con acuerdos y condiciones.
} 
partos con desproporción cefalopélvica, diabetes gestacional y estrechez del canal blanco, entre otros (Díaz, Sanhueza, Yaksic, 2002).

En términos sociales, las niñas y jóvenes ven encarecida su situación socioeconómica y su oportunidad de movilidad, teniendo que abandonar el estudio y en ocasiones saliendo de la casa de sus padres para "juntarse" con hombres mayores que pueden hasta doblarle la edad.

En términos generales las mujeres tienen poco control sobre su sexualidad, de un total de mujeres entrevistadas el $44 \%$ declaró que cuando estuvo embarazada no lo deseaba (Pernudi, Sandoval y Solano, 2007).

Una parte considerable de las mujeres tanto panameñas como costarricenses acuden a los servicios de salud de las comunidades más cercanas, para recibir un control prenatal básico. Esto con el fin de monitorear el desarrollo fetal y calcular una fecha aproximada de nacimiento, ya que cuando se vive en la montaña o se trabaja en una finca cafetalera que en ocasiones es de difícil acceso. En estos casos las parteras pueden ser la diferencia entre la vida y la muerte.

La partería, como práctica no ha desaparecido ni del territorio indígena ni de las zonas de trabajo temporal, culturalmente hablando. Sin embargo, es importante resaltar que estas mujeres especialistas han sido, en el caso de Costa Rica, muy perseguidas, lo que ha provocado dificultades para un remplazo generacional con el objetivo que el conocimiento se siga transmitiendo.

Las mujeres parteras según lo relatado por Alphonse (1978), son "Mubaí", aquellos individuos especiales que nacen con los conocimientos y el carisma de ayudar a los enfermos, y además son los preferidos de Dios.

En la experiencia del Área de Salud de Coto Brus (frontera con Panamá) se ha construido un discurso alrededor de la incorporación del saber de estas mujeres en la atención de los partos institucionalizados, sin embargo, en la práctica se ha avanzado poco en acercarse al conocimiento desde un diálogo de saberes.

Las parteras han sido relegadas a una práctica desde las sombras, a una posición de observadora-acompañante en el momento del alumbramiento en los hospitales. Más allá de los discursos políticamente correctos, la partería se ha abordado desde la sala de partos como una necesidad de folklore y no como un conocimiento legítimo y valioso.

Entre las labores de la partera se reconoce: el acompañamiento que se le da a las madres semanas después, especialmente a aquellas que son "primerizas". Entre las mujeres que están embarazadas, cuando se reflexiona sobre la atención del embarazo y del futuro parto, la mayoría a pesar de planear asistir al servicio institucional manifiestan que les gustaría tener las condiciones materiales para que el alumbramiento se diera en el hogar. Sin embargo, en muchas ocasiones los lugares donde están albergados carecen de servicios básicos como agua o electricidad.

El embarazo significa para las mujeres indígenas cambios en su rutina de trabajo, evitando "alzar cosas pesadas", la relación íntima con la pareja, y variaciones en la alimentación, pues durante los meses de 
gestación se circunscribirá principalmente a "caldos". Durante el embarazo no debe de consumir nada que esté amarrado, como por ejemplo tamales, pues se cree que esto puede provocar que el niño o niña al nacer tenga el cordón umbilical amarrado en el cuello.

Para los malestares propios del embarazo, las mujeres pueden acudir al curandero, que a base de infusiones y mixturas de plantas le ayuda aliviar dichos malestares. En el caso de los trabajadores temporales en las fincas, a veces no se cuenta con curandero o parteras como personas especializadas, pero la función social es cubierta por alguna abuela o abuelo.

La mujer embarazada no debe compartir los enseres de la casa como platos y vasos; tampoco debe de dormir con los niños o niñas en la misma cama pues estos corren el peligro de quedar con "pereza", ni pasar por encima de otra persona.

Durante el embarazo a las mujeres indígenas se les da instrucción de caminar rápido y de vaciar sus chacras cuando llegan del campo o de alguna diligencia, para que el nacimiento se de forma expedita y sin complicaciones. En esta misma línea se cree que los enseres de la cocina deben estar siempre limpios para que la piel del niño o niña sea de la misma manera.

\title{
3.3 El parto y post-parto
}

El nacimiento de un niño o niña en el universo cultural de los ngäbes y buglés, se realiza en aislamiento del grupo familiar ya sea en una casa aparte de la familia o en la montaña, pero siempre en compañía de la partera y algunas otras mujeres. La parturienta se encuentra en condición de tabú (bukurú) durante todo el embarazo hasta que sea purificada por el humo del tabaco luego del alumbramiento (Torres de Araúz,1999: 315).

Uno de los principales desacuerdos entre el saber tradicional y la medicina institucionalizada, ha sido la elección de la mujer a parir en posición vertical, de cuclillas y agarrándose de un bejuco o calabaza que guinda del techo. En esta posición la partera o alguna ayudante ayuda a la mujer en labor de parto a que con cada contracción se mueva hacia arriba (guindándose).

\begin{abstract}
Se debe tener un mecate para que la señora esté sentada y se esté guindado de eso, con una señora que le esté agarrando la pata para que nazca rápido el bebé, con una calabaza guindando, así como dice ella, y le dan jugo de caña caliente (Ofelia Atencio Santos (mujer indígena), en discusión con la autora, Territorio indígena de Coto Brus, noviembre 2007).
\end{abstract}

De las mujeres que han tenido experiencia de parto institucionalizado relatan que, durante la atención en el hospital, años atrás, fueron obligadas a parir en posición horizontal al calor de regañadas y hasta violencia física (como ser maniatadas a la cama). Esto con los años ha cambiado, pero no ha desaparecido del todo. Dicha experiencia se hace más crítica cuando el personal de salud no explica lo 
que sucede en el proceso (cosa que la partera si hace), no se dirigen a la mujer como persona, no permiten compañía, no hablan su lengua y tratan de apresurar los partos mediante medicalización.

Para las mujeres indígenas el momento del alumbramiento, el embarazo y el post parto son espacios que se deben de compartir solamente entre mujeres; esta situación es una de las principales fricciones con la atención estatal de la salud donde con frecuencia los equipos de atención pueden estar compuestos por hombres. Dicha dificultad se complementa con los protocolos ${ }^{6}$ definidos para la atención del cuerpo de las mujeres y de los recién nacidos, que las mujeres los definen como "invasores", "violentos" o que no respetan los tiempos de los cuerpos mismos.

En el parto tradicional la mujer en labor de parto es ayudada mediante algunas bebidas, tales como el jugo de caña caliente, cogollos de café caliente, bebidas a base de pimienta, un batido de huevo con agua caliente, entre otros.

Desde la partería tradicional, lo expedito y poco complejo de un parto depende de ciertos cuidados que se consideran indispensables durante el embarazo, uno de ellos es cuidar la posición en la que se duerme pues no se puede dar vueltas durante el descanso, ya que el niño se va a voltear y durante la labor de parto no se acomodará.

Antes no nacían los chiquillos así, atravesado,
asentadito, así porque, primer embarazo la abuela le
cuida a uno, la mamá le cuida y no le dejan dormir así,
dar vuelta...Eso me decía mi abuela a mí, si usted se
cansa, se sienta, se levanta con cuidadito se vuelca
(Ofelia Atencio Santos (mujer indígena), en discusión
con la autora, Territorio indígena de Coto Brus,
noviembre 2007).

Para las mujeres es importante que el ombligo se corte cuando la mujer ha expulsado toda la placenta de su organismo, por lo general se puede tardar de unos minutos a una hora. Para que el ombligo le cicatrice rápido y de buena manera, se quema la tuza del maíz y el carbón que queda se muele y se le aplica durante cuatro días hasta que este seco.

Es muy importante bañar al niño con agua tibia y luego ungirlo con la primera leche de la madre también por cuatro días, esta práctica tiene el propósito de que al niño "no le salga mucho pelo en el cuerpo". Además, se le debe masajear la cabeza, la cara y el cuerpo al niño para que termine de formarse.

Con la finalidad de que el recién nacido no sea asmático, la madre debe extraer con el dedo o una moneda la flema de la boca y enterrarla conjuntamente el ombligo. La mujer debe sepultar la placenta, y de acuerdo con la profundidad a que la ponga así nacerá en tiempo el próximo hijo, si le coloca una piedra encima no volverá a quedar en cinta.

\footnotetext{
${ }^{6}$ Los tactos vaginales, las maniobras sobre el vientre para que el niño se ponga en posición de expulsión, "el piquete" o corte de la vulva hacia el ano (zona llamada perineo) para agrandar el canal vaginal, entre otros.
} 
Cuando la mujer tiene problemas para producir la leche materna, se le debe de preparar una bebida a base de hojas de yuca, además se puede consumir el fruto de la yuca tierno para que la mujer lo coma en un "guacho". Estos son algunos consejos que le daría la partera en esas semanas de acompañamiento.

El cacao se utiliza en esta etapa por dos razones, cuando el niño recién nacido no quiere tomar leche materna y para que la parturienta se proteja de los malos espíritus. Luego del parto la mujer guarda reposo durante cuatro días, en ese mismo tiempo tendrá ayuno, se debe de bañar con agua tibia, no debe de comer cosas frescas, solo pollo ahumado o cocinado y arroz guacho. Durante este tiempo el binomio madre e hijo se encuentran aislados del resto la familia.

Cuando el niño está recién nacido, se le aplica en la frente una pasta conocida como caraña hedionda, esta pasta posee un olor fuerte que sirve para alejar a los malos espíritus del recién nacido.

En el escenario de las fincas de trabajo, en el caso de Costa Rica se han reportado muertes de niños en los primeros meses de vida principalmente por problemas respiratorios. El hacinamiento, el frio en el caso de las zonas altas y el humo de los fogones son caldo de cultivo para el desarrollo de problemas de este tipo. Solo en el año 1998 para la fecha del 17 de diciembre, habían fallecido ya 3 niños hijos de trabajadores temporales del café en San Lorenzo de Tarrazú. Emilia Abrico Palacios de nueve meses fue la víctima, que había sido precedida por Abelino Abrico Palacios de tres meses y Florida Miranda Miranda de tres meses y medio, según se informó en reportaje de La Nación del 17 de diciembre de 1998.

\subsection{Los servicios estales de atención de la salud}

Las identidades nacionales, se consideran como formaciones construidas sobre la base de diferencias y desigualdades; las mismas no se deben abordar bajo una percepción estática y en ocasiones se dan como naturales los hechos que se construyen socialmente. La diversidad cultural confirma que no hay una única identidad nacional, sino múltiples y diversas bajo relaciones de subordinación. Las identidades nacionales tienen la capacidad de expulsar atributos, sectores o elementos que no coinciden con la nacionalidad deseada como es el caso de los pueblos indígenas.

Cuando se realiza una revisión de las referencias que hacen los medios de comunicación, se puede observar una ausencia importante de estos colectivos y sus problemas, dejando claro que Costa Rica está muy lejos no solo de reconocerse diversa sino de asumir esta deuda histórica y social.

La pobreza, la exclusión, la falta de tecnología, las costumbres "extrañas" a las que por azares del destino no siguen nombrando como "salvajes", son algunos de los tópicos a partir de los cuales se hace referencia en prensa, radio y televisión. En el caso particular de los ngäbes y buglés, es prácticamente generalizado el calificativo de foráneo, 
extranjero, refugiado, movilizado, panameño y en general un otro muy lejano al "nosotros".

También es común que algunas de estas notas periodísticas, se centren en la "carga social" que significan para el Estado los servicios (de atención y prevención) brindados a los trabajadores temporales y sus familias.

Si bien los inmigrantes temporales ayudan a esta zona cafetalera a recoger la cosecha del grano, su presencia también representa un problema.

Esto debido a la carga económica que significa su atención médica y al riesgo de transmisión de malaria y tuberculosis, enfermedades que están golpeando al territorio panameño" (Sin autor, "Esperan masiva llegada de guaymíes para recoger café", La Nación (San José), 23 de agosto del 2004). Esta idea se complementa con el imaginario de que los pueblos indígenas gozan de vivir en condiciones de aislamiento y miseria, y que ciertas condiciones de su forma de vida responden a la "costumbre" y no a la exclusión.

Los guaymíes acostumbran a vivir en barracas
minúsculas, en grupos hasta de 20 personas, y allí
cocinan con leña" (Monserrat Solano Carboni, "Otra
guaymí muere (La Nación, 17 de diciembre de 1998).

A lo largo de estos últimos 10 años se han mejorado de manera reconocible, las estadísticas sobre la mortalidad materna e infantil en la población indígena para la región fronteriza, sin embargo, hay que detenerse en las fórmulas y concepciones de la igualdad que se juegan en la atención de la salud cuando se trata de los reclamos que los sectores indígenas realizan acerca de estos servicios.

En este punto es fundamental revisar las demandas y las experiencias de las mujeres, y detectar dónde radica la dificultad $\mathrm{o}$ dificultades que subyacen en el discurso oficial acerca de las "diferencias culturales". Claramente como he tratado de esbozar, el mundo de la atención del cuerpo de las mujeres y los niños desde la visión indígena refiere a la necesidad de comprender el proceso como un momento donde la mujer tiene control sobre su cuerpo y el de su hijo, sea respetada como un ser integral en materia y espíritu, y goce de compañía y afecto. Estas declaraciones de las mujeres me llevan a plantear que, lo que ocurre en principio es un problema de violencia obstétrica, que se ha interpretado únicamente como un problema intercultural. En este escenario de atención de la salud, es imposible hablar de acciones interculturales cuando no se han superado condiciones básicas para establecer un diálogo de saberes en condiciones de equidad, así como un abandono de la visión folclórica y estática de la cultura de los pueblos indígenas. Es por eso que las acciones terminan siendo limitadas a batas de maternidad con diseños alusivo a lo tradicional, salas de parto decoradas con pinturas y motivos "alegóricos" al mundo indígena, entre otros; es decir las trasformaciones son más ornamentales o estéticas que relacionales. 
Esta asimetría se repite cuando las comunidades no son incorporadas a los debates en condiciones de negociación sino como simples espectadores, cuando se adaptan superficialmente estrategias utilizadas con el resto de la población a la población indígena, y cuando se promueve la institucionalización de saberes (como el aprendizaje de la partería) más que la comprensión de los mismos y el respeto a su valor social, cultural y científico.

En un estudio desarrollado entre trabajadores de salud del cordón fronterizo, se detectó que el $34 \%$ considera que las personas indígenas tienen malos hábitos higiénicos, y un $23 \%$ considera que tienen problemas de carácter que intervienen negativamente en sus "posibilidades" de socialización y de incorporación. Finalmente, un $10.3 \%$ del personal de salud se manifiesta en desacuerdo a la afirmación que los servicios de salud se adapten culturalmente desde las necesidades de la población pues desde su percepción hay una serie de limitantes que hace realmente posible este tránsito (Pernudi, Sandoval y Solano, 2007).

\section{Conclusiones.}

Como he tratado de retratar a lo largo de estas páginas, la situación del pueblo ngäbe y buglé en la frontera entre Costa Rica y Panamá es compleja, y deja ver que, en materia de inclusión, acceso a servicios y políticas laborales el país en rezago. Es decir, pareciera que lo que sucede en las fincas de café, plantaciones de banano y en los territorios indígenas obedeciera a un país aparte.

Pero la situación se torna mucho más compleja si, además, la persona que migra es mujer y está embarazada. En ese caso la situación se puede tornar aterradora, pues no se cuenta con los medios materiales para gozar de una gestación saludable, se ha desarraigado de su red de cuidados y afectos, y las políticas estatales de atención de la salud son incompresibles y violentas.

En el caso costarricense las prácticas institucionales que en buena teoría deberían de velar por la incorporación del mundo cultural indígena en la atención de la salud, han quedado reducidas a la anexión de prácticas que más que obedecer a la concepción indígena del alumbramiento, responden a estereotipos que tiene la institución sobre su cultura.

\section{Referencias bibliográficas}

ATENCIO Rodríguez, Felicita (mujer indígena), en discusión con la autora, Territorio indígena de Coto Brus, noviembre 2007.

ATENCIO Santos, Ofelia (mujer indígena), en discusión con la autora, Territorio indígena de Coto Brus, noviembre 2007.

ALPHONSE, Ephraim. Costumbres, folklore y leyendas guaymí. En Actas del V Simposio Nacional de antropología, arqueología y etnohistoria de Panamá. Panamá: INAC. 1978 
ARguedAS RAMíREZ, Gabriela. La violencia obstétrica: propuesta conceptual a partir de la experiencia costarricense. Cuadernos Intercambio sobre Centroamérica y el Caribe (1): 145-169. 2014

BARABAS, Alicia. "Cosmovisiones y etnoterritorialidad en las culturas indígenas de Oaxaca". Antípoda. Revista de antropología y arquelogía (7): 119-139. 2008

BARRANTES, Ramiro. "La estructura poblacional de dos grupos indígenas guaymí de Costa Rica." Revista médica del Hospital Nacional de Niños (1 y 2) (1982): 297- 307.

BARQUERO, Marvin, "Familia indígena sufre penuria bajo un puente", La Nación (San José), 1 de octubre 2006.

BARSLEY, Julie. El cuerpo como territorio de rebeldía. Venezuela: Misión alma mater. 2008.

BORGE Carvajal, "Carlos. Los indios de Costa Rica de su negación a su reivindicación." En Primer congreso científico sobre pueblos indígenas de Costa Rica y sus fronteras. Costa Rica-EUNED. 1998

XI Censo de Población y VII de Vivienda, Instituto Nacional de Estadística y Censo, Panamá, 2010.

X Censo Nacional de Población y VI de Vivienda, Instituto Nacional de Estadística y Censo, Costa Rica, 2011.

CONSTENLA Umaña, Adolfo. Las lenguas del Área Intermedia: introducción a su estudio a real. Costa Rica: Editorial de la Universidad de Costa Rica.1991

CLERICO, Laura y Aldao, Martín. "La igualdad como redistribución y como reconocimiento: Derechos de los pueblos indígenas y Corte Interamericana de derechos humanos." Estudios constitucionales (9) (2011):157-198.

DíAZ, Angélica, Sanhueza, Pablo y Yaksic, Nicole. "Riesgos obstétricos en el embarazo adolescente: Estudio comparativo de resultados obstétricos y perinatales con pacientes adultas." Revista chilena de obstetricia y ginecología67(6) (2002) :481-487.

Guevara Berger, Marcos. Perfil de los pueblos indígenas de Costa Rica. Informe técnico. Costa Rica: RUTA/ Banco Mundial. 2000.

GUPTA, J., \& Nikodem, C. "Maternal Posture in Labour." European Journal of Obstetrics \& Gynecology and Reproductive Biology (2), 273-277. 2000.

HasemanN, George, Lara Pinto, Gloria y Cruz Sandoval, Fernando. Los indios de Centroamérica. España: Fundación MAPFRE.1996.

LARA, Sara María. "El papel de las mujeres en las migraciones y en la movilidad de los grupos indígenas de México." En Las mujeres indígenas de América Latina en los procesos migratorios, 21-40. Costa Rica: Instituto Interamericano de Derechos Humanos. (2009)

MORALES, Abelardo y Lobo, Diego. Mejorando la situación socio laboral de la población móvil ngäbe buglé en Costa Rica y Panamá. Costa Rica: FLACSO. (2014)

PERNUDI, Vilma, Sandoval Irma y Solano Ana Sofia. Incorporación de criterios interculturales en la atención materno-infantil de la población ngäbebuglé en el territorio indígena de Coto Brus, Costa Rica. Informe técnico. Costa Rica: UNA-CCSS-UNICEF. (2007)

PELÁEZ Mendoza, Jorge. "Adolescente embarazada: características y riesgos." Revista Cubana de Obstetricia y Ginecología23(1) (1997):13-17.

QUESADA, Juan Diego. Las lenguas indígenas de la Costa Rica actual. Revista WANI. (2012): 19-24. 
SOLANO Carboni, Monserrat. "Otra guaymí muere", La Nación (San José), 17 de diciembre de 1998).

TORRES de Araúz, Reina. Panamá Indígena. Panamá: Biblioteca de la nacionalidad. 1999.

PlATT, Tristán. El feto agresivo. Parto, formación de la persona y mito historia. Estudios atacameños (22) (2002); 127-155.

YouNG, Philip. Ngawbe: tradition and change among the western guaymí of Panamá. Illinois studies in anthropology (7). Estados Unidos: Illinois Press.1971.

“Esperan masiva llegada de guaymíes para recoger café”, La Nación (San José), 23 de agosto del 2004. 
Ambigua, Revista de Investigaciones sobre Género y Estudios

Culturales, n. ${ }^{\circ}$ 7, 2020, pp. 267-288. ISSN: 2386-8708 